\title{
Pengaruh Kegiatan Terhadap Kinerja Jalan di Koridor Jalan Pasar Kembang Surabaya
}

\author{
Atika Septya Ningtyas dan Siti Nurlaela \\ Departemen Teknik Sipil, Institut Teknologi Sepuluh Nopember (ITS) \\ Corresponding Author: nurlaela@urplan.its.ac.id
}

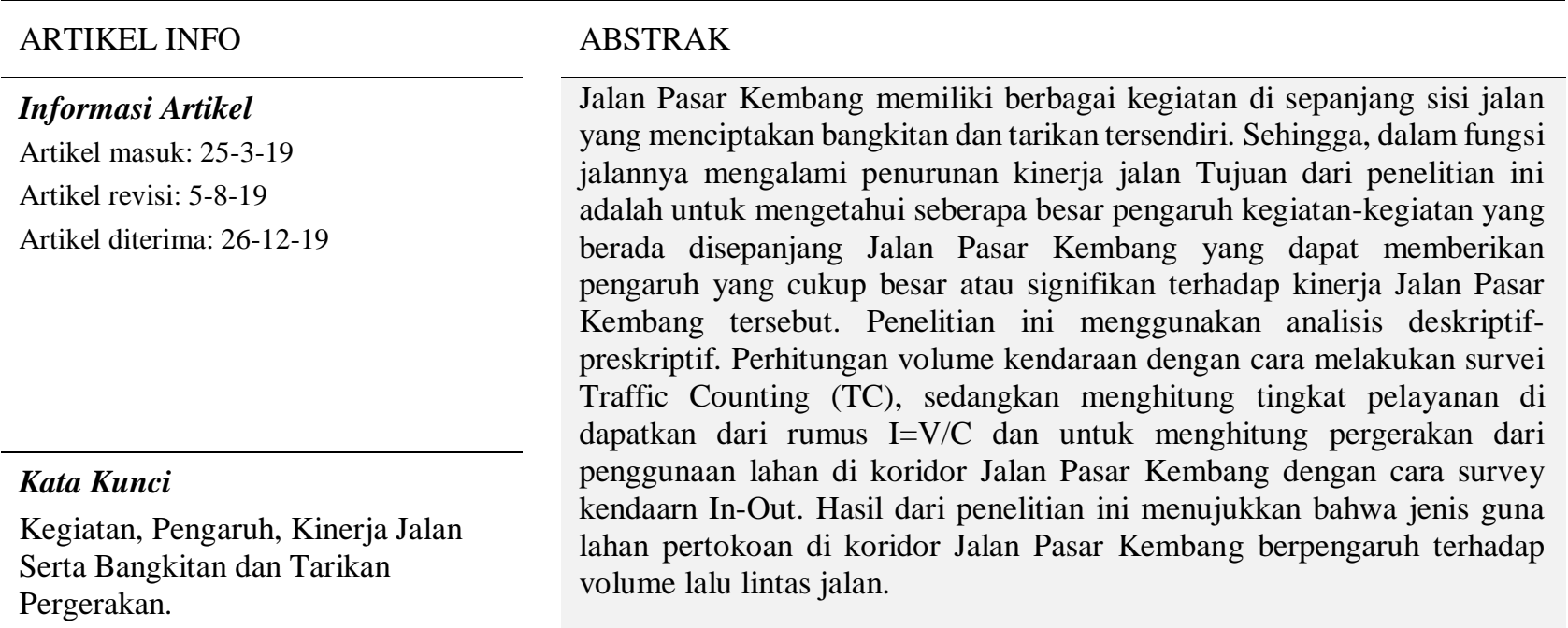

\section{PENDAHULUAN}

Transportasi adalah kegiatan pemindahan barang (muatan) dan penumpang dari suatu tempat ke tempat lain [1]. Dalam transportasi ada dua unsur yang terpenting yaitu pemindahan/pergerakan (movement) dan secara fisik mengubah tempat dari barang (comoditi) dan penumpang ke tempat lain. Transportasi dan tata guna lahan berhubungan sangat erat sehingga biasanya dianggap membentuk satu landuse transport system. Pada hakikatnya kegiatan trasnportasi merupakan penghubung 2 lokasi tata guna lahan yang mungkin bebeda tetapi mungkin pula sama [2].

Pusat perdagangan merupakan salah satu kegiatan yang dapat menimbulkan bangkitan pergerakan yang besar Peningkatan volume juga dapat menimbulkan beberapa permasalahan salah satunya kemacetan. Banyaknya aktifitas dan variasi kegiatan yang dilakukan di pusat bisnis dan perdagangan Pasar Kembang Surabaya sering kali menimbulkan kemacetan pada hari-hari biasa dan jam-jam tertentu yang menyebabkan laju kendaraan terhambat (pergerakan lalu lintasnya) dan pada persimpangan tersebut menyebabkan antrian kendaraan yang melebihi kapasitas jalan di sepanjang Jalan Pasar Kembang [3].

Pada tahun 2008 tingkat utilitas jalan di Jalan Pasar Kembang sebesar 0,38 (jumlah sepeda motor/kapasitas) dan rasio sepeda motor dengan jumlah kendaraan total sebesar 0,85 (smp) pada saat jam puncak pagi hari dan pada sore hari utilitas jalan di Jalan Pasar kembang sebesar 0,40 (jumlah sepeda motor/kapasitas) dan rasio sepeda motor dengan jumlah kendaraan total sebesar 0,83 (smp). Meningkat pada tahun 2013 untuk tingkat utilitas jalan sebesar 0,61 (jumlah sepeda motor/kapasitas) dan rasio sepeda motor dengan jumlah kendaraan total sebesar 0,87 (smp) pada pagi hari dan pada sore hari tingkat utilitas jalan di Pasar Kembang sebesar 0,64 (jumlah sepeda motor/kapasitas) dan rasio sepeda motor dengan jumlah kendaraan total sebesar 0,85 (smp) [4]. Oleh karena itu, penelitian ini diperlukan untukmengetahui pengaruh kegiatan terhadap kinerja Jalan Pasar Kembang Surabaya.

\section{TINJAUAN PUSTAKA}

Dalam tinjauan pustaka terdapat beberapa teori-teori dasar menurut pakar-pakar yang digunakan dalam melaksanakan penelitian ini [5]. Ada beberapa teori yang terkait,yaitu:

Teori transportasi, transportasi didefinisikan sebagai kegiatan memindahkan atau mengangkut sesuatu dari suatu tempat ketempat lain. Transportasi juga merupakan permintaan turunan, (derived demand) yaitu seseorang biasanya melakukan bukan hanya dengan tujuan untuk melakukan perjalanan semata melainkan untuk tujuan dan pada waktu tertentu, seperti pergi bekerja, pergi berbelanja, pergi ke sekolah, dan sebagainya [6]. Teori penggunaan lahan, dasar pemikiran teori ini adalah kegiatan transportasi merupakan penghubung 2 lokasi guna lahan yang mungkin berbeda tetapi mungkin pula. Untuk memenuhi kebutuhannya, manusia melakukan perjalanan antar tata guna lahan tersebut dengan menggunakan sistem jaringan transportasi (misalnya berjalan kaki atau naik angkutan umum) [5]. Teori bangkitan dan tarikan merupakan interaksi antar sistem kegiatan dan sistem jaringan akan menimbulkan pergerakan manusia/barang dalam bentuk pergerakan 
kendaraan. Perubahan pada sistem kegiatan akan membawa pengaruh pada sistem jaringan melalui suatu perubahan tingkat pelayanan pada sistem pergerakan. Begitu pula dengan perubahan pada sistem jaringan akan mengakibatkan sistem kegiatan melalui peningkatan mobilitas dan aksesibilitas dari sistem pergerakan tersebut. Faktor kinerja jalan yang berpengaruh terhadap tingkat pelayanan jalan [7].

\section{METODELOGI PENELITIAN}

\section{A. Jenis Data}

Teknik pengumpulan data terdiri dari beberapa hal, antara lain yaitu survei primer dan survei sekunder yang digunakan untuk mendapatkan data. Teknik pengumpulan data yang digunakan dalam penelitian ini adalah pengumpulan data secara keseluruhan dengan survei primer [8].

\section{B. Pengumpulan Data}

Penelitian dilakukan dengan menggunakan metode pengumpulan data primer melalui observasi dengan melakukan pencatatan informasi yang diperoleh pada saat melakukan pengamatan. Pada penelitian ini, observasi dilakukan dengan cara datang langsung ke lokasi penelitian dan mengamati kondisi eksisiting terkait kondisi lalu lintas, distribusi pergerakan penduduk, serta dominasi bangkitan dan tarikan pergerakan yang ada. Survey perhitungan kendaraan atau traffic counting (TC) dilakukan dengan cara menghitung volume lalu lintas, jenis kendaraan, jumlah kendaraan, kecepatan rata-rata kendaraan yang melintas dan arah perjalanan yang ada pada lokasi penelitian. Untuk menghasilkan volume lalu lintas, setelah melakukan survei, input data yang telah didapat dikonversikan ke dalam satuan smp, dengan nilai ekivalensi mobil penumpang (emp).

Survey geometri Jalan Pasar Kembang untuk mengetahui penampang di Jalan Pasar Kembang dan untuk mengetahui ukuran-ukuran dari bagian Jalan Pasar Kembang Surabaya. Survey kendaraan keluar masuk (inout) mengetahui bangkitan dan tarikan yang dihasilkan oleh adanya aktivitas dari berbagai kegiatan di sepanjang Jalan Pasar kembang yang memiliki angka bangkitan dan tarikan yang tinggi. Survei ini dilakukan dengan menghitung jumlah kendaraan yang masuk dan keluar (melakukan aktivitas parkir) serta melakukan wawancara di pintu masuk dan keluar dari setiap jenis kegiatan yang ada di Jalan Pasar Kembang Surabaya. Karakteristik penggunaan lahan untuk mengetahui jenis-jenis penggunaan lahan di sepanjang koridor Jalan Pasar Kembang Surabaya. Pada penelitian ini sensus penggunaan lahan dilakukan dengan pengamatan langsung yang di fokuskan pada jenis penggunaan lahan dan luas lantai setiap jenis kegiatan eksisting yang ada pada wilayah penelitian. Kemudian dilakukan plotting pada peta wilayah penelitian sehingga dapat diketahui dominasi jenis penggunaan lahan yang ada [9]. Serta dengan melakukan metode pengumpulan data sekunder untuk memperoleh data, informasi, dan peta yang sudah tersedia di sejumlah instansi baik instansi pemerintah maupun swasta. Survey sekunder dilakukan untuk melengkapi data yang diperoleh dari survey primer [10].

\section{ANALISIS DAN PEMBAHASAN}

\section{A. Metode Analisis Penentuan Kinerja Jalan Pasar Kembang}

Pada analisis deskriptif pada penelitian ini mengetahui kemampuan ruas jalan dalam menampung lalu lintas pada keadaan tertentu atau suatu ukuran kuantitatif untuk menerangkan kondisi operasional suatu ruas jalan. Analisis ini nantinya akan digunakan untuk menjelaskan mengenai tingkat pelayanan Jalan Pasar Kembang berdasarkan kondisi-kondisi operasional yang ada di dalam aliran lalu lintas Jalan Pasar Kembang. Maka dari itu dibawah ini menjelaskan mengenai proses analisanya, mulai dari menghitung volume lalu lintas, analisi kapasitas jalan serta menghitung tingkat pelayanan jalan.

\begin{tabular}{ccccccc}
\multicolumn{7}{c}{ Tabel 1. Volume Kendaraan } \\
\hline Jam & Titik & Titik & Titik & Titik & Titik & Titik \\
& 1 & 2 & 3 & 4 & 5 & 6 \\
\hline $07.00-08.00$ & 921 & 1257 & 2071 & 858 & 1582 & 1528 \\
$08.00-09.00$ & 2377 & 1844 & 2688 & 2288 & 2530 & 2494 \\
$12.00-13.00$ & 2412 & 2454 & 2440 & 2267 & 2437 & 1902 \\
$17.00-18.00$ & 2080 & 3065 & 2607 & 3168 & 3003 & 2628 \\
$18.00-19.00$ & 997 & 1503 & 2394 & 1457 & 1447 & 1920 \\
\hline
\end{tabular}

Tabel 1 Menunjukkan volume kendaraan di Jalan Pasar Kembang saat jam puncak dengan satuan smp/jam dengan pembagian 6 titik pengamatan yang telah dilakukan.

Kapasitas jalan adalah jumlah lalu lintas kendaraan maksimum yang dapat dimuat oleh ruas jalan pada waktu tertentu. Analisis ini bertujuan untuk menentukan kapasitas jalan dilihat dari standar yang telah ditetapkan oleh Manual Kapasitas Jalan Indonesia dan dapat ditentukan menggunakan rumus sebagai berikut :

Dimana:

$$
\mathrm{C}=\mathrm{C}_{\mathrm{o}} \times \mathrm{FC}_{\mathrm{w}} \times \mathrm{FC}_{\mathrm{SP}} \times \mathrm{FC}_{\mathrm{SF}} \times \mathrm{FC}_{\mathrm{CS}}
$$

$\mathrm{C} \quad$ = kapasitas ruas jalan (smp/jam)

$\mathrm{C}_{\mathrm{o}} \quad=$ kapasitas dasar ( $\left.\mathrm{smp} / \mathrm{jam}\right)$

$\mathrm{FC}_{\mathrm{w}}$ = faktor penyesuaian lebar jalur lalu lintas

$\mathrm{FC}_{\mathrm{SP}}=$ faktor penyesuaian pemisahan arah

$\mathrm{FC}_{\mathrm{SF}}=$ faktor penyesuaian akibat hambatan samping

$\mathrm{FC}_{\mathrm{CS}}=$ faktor penyesuaian ukuran kota

Sumber : MKJI, 1997

\begin{tabular}{cccccc}
\multicolumn{6}{c}{ Tabel 2. Kapasitas Jalan Pasar Kembang } \\
\hline $\mathbf{C}_{\mathbf{o}}$ & $\mathbf{F C}_{\mathbf{w}}$ & $\mathbf{F C}_{\mathbf{S P}}$ & $\mathbf{F C}_{\mathbf{S F}}$ & $\mathbf{F C}_{\mathbf{C S}}$ & $\mathbf{C}$ \\
\hline 4950 & 0,96 & 1,00 & 0,92 & 1,04 & $4.546,71$ \\
\hline
\end{tabular}

Tabel 2 menjelaskan bahwa faktor penyesuaian kapasitas dasar $\left(\mathrm{C}_{\mathbf{o}}\right)$ di koriodr Jalan Pasar Kembang dengan Tipe jalan : 3/1 (3 lajur dan 1 arah), maka: $\left(\mathrm{C}_{\mathrm{o}}\right)=$ $1650 /$ lajur*3 lajur $=4.950$. Faktor penyesuaian kapasitas $\left(\mathrm{FC}_{\mathrm{w}}\right)$ untuk lebar jalur lalu lintas dengan lebar efektif jalan 3,25 meter, maka $\left(\mathrm{FC}_{\mathrm{w}}\right)=0,96$. Faktor koreksi kapasitas akibat pembagian arah $\left(\mathrm{FC}_{\mathrm{SP}}\right)$ untuk jalan satu arah dan/atau jalan dengan pembatas median, maka faktor koreksi kapasitas akibat pembagian arah adalah 1,00, maka $\left(\mathrm{FC}_{\mathrm{SP}}\right)=1,00$. Faktor penyesuaian akibat gangguan hambatan samping $\left(\mathrm{FC}_{\mathrm{SF}}\right)$ untuk jalan yang memiliki bahu jalan, didasarkan pada lebar bahu jalan efektif dan tingkat gangguan samping sesuai dengan penentuan faktor penyesuaian kapasitas $\left(\mathrm{FC}_{\mathrm{SF}}\right)$ untuk hambatan samping dalam MKJI, 1997. Dengan kondisi lebar bahu jalan selebar 2 meter dan sesuai dengan penentuan hambatan samping yang mengacu pada MKJI, 1997 yaitu memiki 
kelas hambatan samping dengan nilai "VH" atau sangat tinggi serta memiliki lebar bahu efektif $\geq 2 \mathrm{~m}$, maka $\left(\mathrm{FC}_{\mathrm{SF}}\right)=0,92$. Faktor penyesuaian kapasitas $\left(\mathrm{FC}_{\mathrm{CS}}\right)$ untuk ukuran kota dinyatakan dalam jumlah penduduk Kota Surabaya. Jumlah penduduk Kota Surabaya adalah 3.074.490 jiwa pada tahun 2017, maka $\left(\mathrm{FC}_{\mathrm{CS}}\right)=1,04$.

\begin{tabular}{ccccc}
\multicolumn{5}{c}{ Tabel 3. Tingkat Pelayanan Jalan Ruas 1 titik 1 } \\
\hline Waktu & $\begin{array}{c}\text { Volume } \\
(\mathrm{V}) \\
(\mathrm{smp} / \mathrm{jam})\end{array}$ & $\begin{array}{c}\text { Kapasitas } \\
\text { jalan }(\mathrm{C}) \\
(\mathrm{smp} / \mathrm{jam})\end{array}$ & $\begin{array}{c}\mathrm{DS} \\
(\mathrm{V} / \mathrm{C})\end{array}$ & $\begin{array}{c}\text { Tingkat } \\
\text { Pelayanan }\end{array}$ \\
\hline $\begin{array}{l}\text { 07.00- } \\
08.00\end{array}$ & 920,6 & $4.546,71$ & 0,20 & $\mathrm{~A}$ \\
$08.00-$ & 2376,7 & $4.546,71$ & 0,52 & $\mathrm{C}$ \\
09.00 & & & & \\
& & & & $\mathrm{C}$ \\
$12.00-$ & 2412,35 & $4.546,71$ & 0,53 & \\
13.00 & & & & $\mathrm{C}$ \\
$17.00-$ & 2080,3 & $4.546,71$ & 0,46 & $\mathrm{~B}$ \\
18.00 & 997,1 & $4.546,71$ & 0,22 & \\
$18.00-$ & & & & \\
19.00 & & &
\end{tabular}

Tabel 3 menunjukkan bahwa rentang tingkat pelayanan Jalan Pasar Kembang pada ruas I titik 1 ialah antara A sampai dengan C. Nilai LOS terendah terjadi pada pukul 12.00-13.00 dengan nilai DS ( $v / c$ ratio) senilai 0,53 smp/jam.. Hal ini disebabkan oleh pergerakan lalu lintas akibat aktifitas kegiatan di sisi jalan dan jam istirahat para pekerja. Dengan nilai LOS yaitu C, maka berdasarkan nilai sebesar $0,53 \mathrm{smp} / \mathrm{jam}$, kondisi tersebut tergolong dalam lalu lintas yang cukup stabil, meskipun terdapat tundaan, namun masih layak diterima.

Tabel 4. Tingkat Pelayanan Jalan Ruas 1 titik 2

\begin{tabular}{lcccc}
\hline \multicolumn{1}{c}{ Waktu } & $\begin{array}{c}\text { Volume } \\
(\mathrm{V}) \\
(\mathrm{smp} / \mathrm{jam})\end{array}$ & $\begin{array}{c}\text { Kapasitas } \\
\text { jalan }(\mathrm{C}) \\
(\mathrm{smp} / \mathrm{jam})\end{array}$ & $\begin{array}{c}\mathrm{DS} \\
(\mathrm{V} / \mathrm{C})\end{array}$ & $\begin{array}{c}\text { Tingkat } \\
\text { Pelayanan }\end{array}$ \\
\hline $\begin{array}{l}07.00- \\
08.00\end{array}$ & 1256,8 & $3.031,14$ & 0,41 & $\mathrm{~B}$ \\
$08.00-$ & 1843,9 & $3.031,14$ & 0,61 & $\mathrm{C}$ \\
09.00 & & & & \\
$12.00-$ & 2454,25 & $3.031,14$ & 0,81 & $\mathrm{D}$ \\
13.00 & & & & \\
$17.00-$ & 3064,7 & $3.031,14$ & 1,01 & $\mathrm{~F}$ \\
18.00 & & $3.031,14$ & 0,50 & $\mathrm{C}$ \\
$18.00-$ & 1502,85 & & & \\
19.00 & & & & \\
\hline
\end{tabular}

Tabel 4 menunjukkan bahwa rentang tingkat pelayanan Jalan Pasar Kembang pada ruas I titik 2 ialah antara B sampai dengan F. Nilai LOS terendah terjadi pada pukul 17.00-18.00 dengan nilai DS ( $v / c$ ratio) senilai 1,01 smp/jam. Hal ini desebabkan oleh pergerakan lalu lintas akibat para pekerja baik dari ruas jalan wilayah penilitian maupun pekerja dari luar wilayah penlitian yang melintas meninggalkan tempat berkerja (kantor). Dengan nilai LOS yaitu F, maka berdasarkan nilai sebesar 1,01 smp/jam, kondisi tersebut tergolong dalam arus lalu lintas yang dipaksakan atau macet pada kecepatan yang rendah, mengakibatkan antrian kendaraan yang panjang dan terjadi hambatan-hambatan yang besar.

Untuk menghitung bangkitan dan tarikan lalu lintas yang tercipta karena adanya berbagai kegiatan di sepanjang Jalan Pasar Kembang, dilakukan dengan Mendata jenis, jumlah, luas kapling serta jumlah lantai tiap bangunan di Jalan Pasar Kembang, membagi jenis kegiatan berdasarkan tingkatan luasan kapling, menghitung volume kendaraan yang masuk dan keluar pada tiap kegiatan (yang memiliki bangkitan dan tarikan yang tinggi pada tiap ruas) yang melakukan kegiatan parkir, menganalisa tingkat bangkitan dan tarikan pada setiap ruas di Jalan Pasar Kembang Surabaya.

Tabel 5. Pengaruh Penggunaan Lahan terhada Kinerja Jalan Pasar Kembang

\begin{tabular}{|c|c|c|c|c|c|c|}
\hline No & $\begin{array}{l}\text { Penggunaa } \\
\text { n Lahan }\end{array}$ & $\begin{array}{c}\text { Juml } \\
\text { ah } \\
\text { Ban } \\
\text { guna } \\
\text { n }\end{array}$ & $\begin{array}{c}\text { Total } \\
\text { Volume } \\
\text { Kendara } \\
\text { an yang } \\
\text { Melintas } \\
\text { (smp/jam } \\
\text { ) }\end{array}$ & $\begin{array}{c}\text { Luas } \\
\text { Kapli } \\
\text { ng } \\
\text { Bang } \\
\text { unan } \\
\left(\mathrm{m}^{2}\right)\end{array}$ & $\begin{array}{l}\text { Total } \\
\text { trip } \\
\text { (rata- } \\
\text { rata trip } \\
\text { rate*tot } \\
\text { al luas } \\
\text { kaplig } \\
\text { bangun } \\
\text { an) }\end{array}$ & $\begin{array}{c}\text { Pros } \\
\text { entas } \\
\mathrm{e} \\
(\%)\end{array}$ \\
\hline 1. & Pertokoan & 56 & 2074,0 & 3934 & 236,04 & $\begin{array}{l}11,3 \\
8 \%\end{array}$ \\
\hline 2. & Perkantoran & 9 & 2074,0 & 458 & 27,48 & $\begin{array}{c}1,32 \\
\%\end{array}$ \\
\hline 3. & $\begin{array}{l}\text { Fasilitas } \\
\text { Umum }\end{array}$ & 3 & 2074,0 & 367 & 22,02 & $\begin{array}{c}1,06 \\
\%\end{array}$ \\
\hline 4. & $\begin{array}{l}\text { Rumah } \\
\text { Makan }\end{array}$ & 6 & 2074,0 & 255 & 15,3 & $\begin{array}{c}0,74 \\
\%\end{array}$ \\
\hline \multirow[t]{2}{*}{5.} & Jasa & 2 & 2074,0 & 121 & 7,26 & $\begin{array}{c}0,35 \\
\%\end{array}$ \\
\hline & $\begin{array}{c}\text { Total } \\
\text { RUAS } 2\end{array}$ & 76 & & 5135 & 308,1 & $15 \%$ \\
\hline 1. & Pertokoan & 40 & 2100,6 & 2463 & 147,78 & $7,0 \%$ \\
\hline 2. & Perkantoran & 6 & 2100,6 & 1442 & 86,52 & $4,1 \%$ \\
\hline 3. & $\begin{array}{l}\text { Fasilitas } \\
\text { Umum }\end{array}$ & 4 & 2100,6 & 384 & 23,04 & $1,1 \%$ \\
\hline 4. & $\begin{array}{l}\text { Rumah } \\
\text { Makan }\end{array}$ & 8 & 2100,6 & 429 & 25,74 & $1,2 \%$ \\
\hline 5. & $\begin{array}{l}\text { Jasa } \\
\text { Total }\end{array}$ & $\begin{array}{l}40 \\
58 \\
\end{array}$ & 2100,6 & $\begin{array}{c}0 \\
4718 \\
\end{array}$ & $\begin{array}{c}0 \\
283,08\end{array}$ & $\begin{array}{l}0,0 \% \\
13 \% \\
\end{array}$ \\
\hline
\end{tabular}

Dari tabel di atas, dapat diketahui bahwa jenis guna lahan pertokoan, perkantoran, fasilitas umum, dan jasa pada ruas 1 berpengaruh terhadap ruas jalan sisi kanan dari arah utara ke selatan. Dari data diatas, volume bangkitan dan tarikan yang tertinggi diakibatkan adanya kegiatan pertokoan yang berada disisi jalan dengan nilai volume sebesar 236,04smp/jam dengan prosentase sebesar $11,38 \%$. Sehingga, dari data tebel diatas tersebut menunjukkan penggunaan lahan di ruas 1 mempunyai pengaruh pada volume lalu lintas Jalan Pasar Kembang sebesar $0,35 \%$ sampai dengan $11,38 \%$.

Pada ruas 2, jenis guna lahan pertokoan, perkantoran, fasilitas umum, dan rumah makan berpengaruh terhadap ruas jalan sisi kiri dari arah selatan ke utara. Dari data diatas, volume bangkitan dan tarikan yang tertinggi diakibatkan adanya kegiatan pertokoan yang berada disisi jalan dengan nilai volume sebesar 147,78smp/jam dengan prosentase sebesar $7 \%$. Sehingga, dari data tebel diatas tersebut menunjukkan penggunaan lahan di ruas 2 mempunyai pengaruh pada volume lalu lintas Jalan Pasar Kembang sebesar 0\% sampai dengan 7\%.Tabel 5

\section{KESIMPULAN}

Dari hasil penelitian yang ditemukan, Pengaruh penggunaan lahan di koridor Jalan Pasar Kembang didominasi oleh kegiatan perdagangan atau pertokoan dan sisanya dipengaruhi oleh jenis kegiatan perkantoran, fasilitas umum, jasa dan rumah makan. Sehingga penggunaan lahan pada penggunaan lahan di ruas 1 mempunyai pengaruh pada volume lalu lintas Jalan Pasar Kembang sebesar 0,35\% sampai dengan $11,38 \%$ dan 
penggunaan lahan di ruas 2 mempunyai pengaruh pada volume lalu lintas Jalan Pasar Kembang sebesar 0\% sampai dengan $7 \%$.

\section{REKOMENDASI}

Berdasarkan hasil penelitian yang telah dilakukan, maka diketahui bahwa pengaruh kegiatan-kegiatan terhadap Jalan Pasar Kembang cukup besar sehingga mempengaruhi tingkat pelayanan atau kinerja jalannya. Oleh karena itu, rekomendasi yang dapat diberikan adalah penertiban terhadap kendaraan yang berhenti di sepanjang koridor Jalan Pasar Kembang, termasuk angkutan umum, taksi maupun kendaraan bermotor lainnya yang dapat mempengaruhi menurunnya kinerja jalan tersebut serta pengaruh kegiatan terbesar di Jalan Pasar Kembang Surabaya adalah jenis kegiatan pertokoan, agar dapat meminimalisir hambatan samping di koridor Jalan Pasar Kembang hendaknya setiap kegiatan pertokoan menyediakan kapasitas untuk parkir kendaraan.

\section{DAFTAR PUSTAKA}

[1] S. Abbas, Manajemen Transportasi. Jakarta: Ghalia Indonesia, 2000.

[2] S. Arikunto, Prosedur Penelitian: Suatu Pendekatan Praktik. Jakarta: Rineka Cipta, 2002.

[3] E. Budiharjo, Kota Berwawasan Lingkungan. Bandung.

[4] Badan Pusat Statistik Kota Surabaya, Kota Surabaya dalam Angka 2017. Surabaya: Badan Pusat Statistik Kota Surabaya, 2017.

[5] Direktorat Jendral Bina Marga, "Departemen Pekerjaan Umum : Manual Kapasitas Jalan (MKJI),” Jakarta, 1997.

[6] M. E. Eliot Hurst, Transportation geography: comments and readings,. McGraw-Hill, 1973.

[7] C. J. Khisty and B. K. Lall, Transportation engineering: an introduction. Prentice Hall, 2003.

[8] F. 1961- Miro, Sistem transportasi kota : teori dan konsep dasar, Ed.1. Tarsito, 1997.

[9] F. Miro, Perencanaan transportasi: untuk mahasiswa, perencana, dan praktisi. Penerbit Erlangga, 2005.

[10] E. K. Morlok, Pengantar teknik dan perencanaan transportasi / Edward K. Morlok; alih bahasa Johan Kelanaputra Hainim. 1978. 